Pathophysiology of Haemostasis and Thrombosis

\title{
Low-Dosage Intravenous Immunoglobulin in the Management of a Patient with Acquired von Willebrand Syndrome Associated with Monoclonal Gammopathy of Undetermined Significance
}

\author{
T. Hayashia H. Yagib H. Suzukia Y. Nonaka ${ }^{a} \quad$ T. Nomura ${ }^{a} \quad$ Y. Sakurai ${ }^{c}$ \\ M. Shibatac M. Matsumoto ${ }^{b}$ Y. Yamamoto ${ }^{b}$ Y. Fujimurab \\ aDivision of Internal Medicine, Tokyo Metropolitan Police Hospital, Tokyo, \\ Departments of ${ }^{b}$ Blood Transfusion Medicine and cPediatrics, Nara Medical University, Kashihara, J apan
}

\section{Key Words}

Acquired von Willebrand syndrome $\cdot$ Monoclonal gammopathy $\cdot$ Inhibitor $\cdot$ Low-dosage immunoglobulin therapy

\begin{abstract}
We report herein the case of a 69-year-old J apanese man with acquired von Willebrand syndrome associated with monoclonal gammopathy of undetermined significance who developed IgG1-k antibodies against von Willebrand factor (VWF). The patient was urged to undergo tooth extractions because of alveolar pyorrhea, and a low-dosage intravenous immunoglobulin (IV-Ig) therapy $(0.3 \mathrm{~g}$ of $\mathrm{IgG} / \mathrm{kg} /$ day for 3 days) was chosen for him. On the 4th day after the infusion, VWF antigen and VWF ristocetin cofactor increased to 40 and $78 \%$ of the control, respectively, and dental extractions were performed successfully. On the 7th day, these values reached a maximum, i.e. 95 and $160 \%$ of the control, respectively. Then, they quickly decreased to 35 and $75 \%$ on the 10th day, and 6 months later, they became 16 and $<3 \%$ of the control, respectively. Upon analysis of plasma VWF multi-
\end{abstract}

mers (VWFMs) in this patient, those with large to medium molecular masses more selectively disappeared before the IV-Ig infusion than did those with small molecular masses. On the 4th day, the pattern of VWFMs was completely normalized and appeared to persist until the 10th day. Six months later, a small amount of large to medium-sized VWFMs was still present, but at 7-8 months, the pattern of VWFMs became almost the same as that before infusion. Throughout the patient's clinical course, the activity of plasma VWF-cleaving protease, which specifically cleaves the Tyr842-Met843 bond of the subunit and reduces its multimeric sizes, was quite normal (95-119\%). These results provided consistent evidence that the selective absence of VWFMs with large to medium molecular masses in this patient is caused by the heightened clearance of a complex of IgG inhibitor and VWFMs from the circulation, presumably through IgG binding to the Fc receptor of macrophages. Furthermore, these results also indicated that a low-dosage IV-Ig therapy is effective enough for hemostatic management for programmed surgery.

\begin{tabular}{ll}
\hline KARGER & ○ 2002 S. Karger AG, Basel \\
Fax +416130612 34 & 1424-8832/02/0321-0033\$18.50/0 \\
$\begin{array}{l}\text { E-Mail karger@karger.ch } \\
\text { www.karger.com }\end{array}$ & $\begin{array}{l}\text { Accessible online at: } \\
\text { www.karger.com/journals/pht }\end{array}$
\end{tabular}

Yoshihiro Fujimura, MD
Department of Blood Transfusion Medicine, Nara Medical University
840 Shijyo-cho, Kashihara, Nara 634-8522 (Japan)
Tel. +81 74422 3051, Fax +81 744290771

E-Mail yfujimur@nmu-gw.naramed-u.ac.jp 


\section{Introduction}

Acquired von Willebrand syndrome (AVWS) is a relatively rare disease characterized by a sudden onset of bleeding in adults who have previously had no such clinical signs [1-4]. Not only clinical manifestations but also laboratory findings are similar between AVWS and von Willebrand disease, a congenital abnormality of von Willebrand factor (VWF) [5]. Therefore, low plasma levels of VWF antigen (VWF-Ag) and ristocetin cofactor (VWF$\mathrm{RCo}$ ) with impaired ristocetin-induced platelet aggregation are the diagnostic hallmarks in both instances. Plasma factor VIII activity (VIII:C) is also diminished in accordance with a reduction in plasma VWF-Ag level because it serves as a carrier protein of factor VIII in the circulation and protects it from in vivo proteolysis [5].

AVWS is often associated with lymphoproliferative, autoimmune and neoplastic disorders. Of these, the most striking association has been reported to be that with monoclonal gammopathy of undetermined significance (MGUS) [3, 4]. The pathogenic mechanisms of AVWS have not been fully elucidated, but the following have been proposed: (1) specific autoantibodies to VWF; (2) nonspecific antibodies that form circulating complexes with VWF, cleared by Fc-bearing cells; (3) absorption of VWF onto malignant cell clones; (4) increased proteolytic degradation of VWF, and (5) loss of larger VWF multimers (VWFMs) in high shear stress conditions [4]. However, the hemostatic management of AVWS can be basically achieved with the following three methods: (1) high-dose infusion of VWF concentrates; (2) the release of VWF from vascular endothelial cells stimulated with 1-deamino-8- $D$-arginine vasopressin (DDAVP), and (3) high-dosage ( $1 \mathrm{~g} / \mathrm{kg} /$ day for 2 days) intravenous immunoglobulin (IV-Ig) therapy which functions by a yet undetermined mechanism $[3,4]$.

In this paper, we report the case of a 69 -year-old Japanese man with AVWS associated with MGUS who developed IgG1-K antibodies against VWF. Dental extractions undergone by this patient were successfully performed under low-dosage IV-Ig therapy. To understand, at least in part, how this therapy worked in this patient, the changes in plasma VWF-Ag, VWF-RCo, VWFMs and inhibitors of VWF were analyzed together with the activity of VWF-cleaving protease (VWF-CPase), which specifically splits the Tyr842-Met843 bond of the VWF subunit and reduces its multimeric sizes [6].

\section{Patient and Methods}

\section{Patient}

A 69-year-old Japanese man was admitted to the Tokyo Metropolitan Police Hospital in June 1998 due to continuous bleeding after a resection of an atheroma on his back. In his past history, the patient had an egg-sized subcutaneous hematoma on his hip with no apparent bruises in April 1994, which was followed by excessive bleeding after incision. At that time, however, his hemostatic screening tests, including platelet count, bleeding time, prothrombin time and activated partial prothrombin time, were all within normal ranges. However, an elevated serum level of $\mathrm{M}$ protein was noted, but no further medical examination was performed. None of his family members has a bleeding tendency.

\section{Assays of VIII:C, VWF-Ag, VWF-RCo and Titer of Inhibitor of $V W F-R C o$}

Citrated platelet-rich plasma and platelet-poor plasma were prepared as described previously [7]. Platelet-poor plasma was stored in small aliquots at $-80^{\circ} \mathrm{C}$ until used. The following assays were performed as described in the respective reports: a one-stage assay of VIII:C [8], a sandwich enzyme-linked immunosorbent assay (ELISA) of VWF-Ag using rabbit polyclonal antibodies [9] and an assay of VWF-RCo using the method of Macfarlane et al. [10]. A 100\% value of VIII:C, VWF-Ag and VWF-RCo was defined as the amount contained in $1 \mathrm{ml}$ of pooled normal plasma.

The titer of inhibitor of VWF-RCo was measured based on the Bethesda method [11], with some modifications. Briefly, after the incubation of an equal volume mixture of normal platelet-poor plasma and patient platelet-poor plasma at $37^{\circ} \mathrm{C}$ for $2 \mathrm{~h}$, the residual VWF-RCo was assayed. One unit of the inhibitor was defined as the amount that inhibits $50 \%$ of VWF-RCo in normal control.

\section{VWF-CPase Activity and Its Inhibitor Titer}

VWF-CPase activity in plasma was assayed according to the method of Furlan et al. [6], but without dialysis, as recently described in detail [12]. The detection limit of VWF-CPase activity in this assay was approximately $3 \%$ of that of the control [12]. The inhibitor of VWF-CPase activity was also determined according to the method of Furlan et al. [6], and its titer was expressed by a Bethesda unit [11, 13].

\section{Analysis of VWFMs}

For this experiment, platelet-poor plasma was collected in the presence of a cocktail of protease inhibitors (final concentrations: $0.38 \% \mathrm{Na}_{3}$-citrate, $5 \mathrm{~m} M$ EDTA-Na $2,6 \mathrm{~m} M$ N-ethylmaleimide, $2 \mathrm{~m} M$ benzamidine- $\mathrm{HCl}$ and $0.2 \mathrm{mg} / \mathrm{ml}$ leupeptin). An SDS- $1.4 \%$ agarose gel electrophoresis and the luminographic detection of VWFMs were performed by the methods of Ruggeri and Zimmerman [14] and Budde et al. [15].

\section{Ig Classes and Subclasses of the Inhibitor of VWF-RCo}

The Ig classes and subclasses of the inhibitor of VWF-RCo were identified by ELISA, as described earlier [16]. Briefly, $50 \mu \mathrm{l}$ of purified VWF $(2 \mu \mathrm{g} / \mathrm{ml})$ was immobilized onto 96 -well microtiter plates. After blocking the nonbinding sites with $2 \%$ bovine serum albumin and washing the plates, $50 \mu \mathrm{l}$ of $1 / 100$ diluted patient plasma was added to the wells. After incubation, Ig bound to immobilized VWF was detected using horseradish peroxidase-conjugated mouse mono- 
Table 1. Laboratory findings upon admission

\begin{tabular}{|c|c|c|c|}
\hline \multicolumn{2}{|l|}{ Peripheral blood } & \multicolumn{2}{|c|}{ Blood chemistry } \\
\hline WBC & $7,800 / \mu 1$ & $\mathrm{TP}$ & $7.1 \mathrm{~g} / \mathrm{dl}$ \\
\hline $\mathrm{RBC}$ & $501 \times 10^{4} / \mu 1$ & Alb & $4.2 \mathrm{~g} / \mathrm{dl}$ \\
\hline $\mathrm{Hb}$ & $15.2 \mathrm{~g} / \mathrm{dl}$ & CRP & $0.7 \mathrm{mg} / \mathrm{dl}$ \\
\hline $\mathrm{Ht}$ & $47.1 \%$ & ALT & $20 \mathrm{IU} / 1$ \\
\hline Reticulocytes & $0.9 \%$ & AST & $19 \mathrm{IU} / 1$ \\
\hline \multirow[t]{2}{*}{ Platelets } & $263 \times 10^{9} / 1$ & $\mathrm{LDH}$ & $175 \mathrm{IU} / 1$ \\
\hline & & $\mathrm{s}-\beta_{2} \mathrm{MG}$ & $1.3 \mathrm{mg} / \mathrm{ml}$ \\
\hline Hemostatic test & & $\mathrm{Na}^{+}$ & $140 \mathrm{mEq} / 1$ \\
\hline PT & $11.6 \mathrm{~s}$ & $\mathrm{~K}^{+}$ & $4.1 \mathrm{mEq} / 1$ \\
\hline APTT & $63.6 \mathrm{~s}$ & $\mathrm{Cl}^{-}$ & $192 \mathrm{mEq} / 1$ \\
\hline Fibrinogen & $308 \mathrm{mg} / \mathrm{dl}$ & $\mathrm{Ca}^{2+}$ & $4.5 \mathrm{mEq} / 1$ \\
\hline VIII:C & $4 \%$ & $\operatorname{IgG}$ & $1,694 \mathrm{mg} / \mathrm{dl}$ \\
\hline VWF-Ag & $6 \%$ & $\operatorname{IgG} 1$ & $86.50 \%$ \\
\hline VWF-RCo & $<3 \%$ & $\mathrm{IgG} 2$ & $9.85 \%$ \\
\hline Platelet aggregation & & IgG3 & $3.16 \%$ \\
\hline Ristocetin $(1.2 \mathrm{mg} / \mathrm{ml})$ & defective & IgG4 & $0.49 \%$ \\
\hline $\operatorname{ADP}(2 \mu \mathrm{g} / \mathrm{ml})$ & normal & $\operatorname{Ig} \mathrm{A}$ & $55.0 \mathrm{mg} / \mathrm{dl}$ \\
\hline \multirow[t]{4}{*}{ Collagen $(2 \mu \mathrm{g} / \mathrm{ml})$} & normal & $\operatorname{IgM}$ & $41.0 \mathrm{mg} / \mathrm{dl}$ \\
\hline & & $\mathrm{IgD}$ & $15 \%$ \\
\hline & & $\operatorname{IgE}$ & $26 \mathrm{U} / \mathrm{ml}$ \\
\hline & & M-protein & IgG1-к \\
\hline
\end{tabular}

clonal IgG against human IgG1, IgG2, IgG3, IgG4 and IgM (The Binding Site Limited, Birmingham, UK).

Plasma IgG was purified using a protein A-sepharose CL-6B column according to the manufacturer's instructions.

\section{Results}

Laboratory findings of the patient upon admission (June 1998) are shown in table 1. Of these, an elevated level of IgG1-K monoclonal protein was remarkable. Bence-Jones protein was not detected. In his hemostatic tests, platelet count and prothrombin time were both normal, but activated partial prothrombin time was prolonged. Furthermore, his ristocetin-induced platelet aggregation was totally defective, and low levels of VIII:C and VWF-Ag were demonstrated. Ristocetin-induced platelet aggregation using an equal volume mixture of normal platelet-rich plasma and patient platelet-poor plasma, incubated at $37^{\circ} \mathrm{C}$ for $5 \mathrm{~min}$, failed to demonstrate the presence of an inhibitor of VWF-RCo (data not shown). However, residual VWF-RCo assayed by the Bethesda method after $2 \mathrm{~h}$ of incubation clearly demonstrated the presence of an inhibitor of VWF-RCo with a titer of $7.0 \mathrm{U} / \mathrm{ml}$ in this patient. Furthermore, the fallthrough fractions of patient plasma from a protein Asepharose CL-6B column had no inhibitory activity on
VWF-RCo, whereas the IgG eluted from the column did have such activity. These results unambiguously indicated that the inhibitor is IgG (data not shown). Taking these results together, the patient was diagnosed as having AVWS associated with MGUS. ELISA, using immobilized VWF, confirmed the presence of anti-VWF alloantibodies (IgG type) that belong to the IgG1 subclass. Neither antibodies of other subclasses of IgG nor of IgM were demonstrated (fig. 1).

The patient was urged to undergo tooth extractions because of alveolar pyorrhea. A low-dosage IV-Ig therapy was chosen for him, and a dose of $0.3 \mathrm{~g}$ of Ig (sulfonated IgG, Venilon, Teijin Co.)/kg was infused on March 19, 1999, and for the following 2 days. On the 4th day after the infusion, VWF-Ag and VWF-RCo increased to 40 and $78 \%$ of the control, respectively, and on that day, dental extractions of 7 and 8 were performed without excessive bleeding. On the 7th day, VWF-Ag and VWF-RCo reached the maximum values, i.e. 95 and $160 \%$ of the control, respectively. Then, these values quickly decreased to 35 and $75 \%$ on the 10th day, and 6 months later, they became 16 and $<3 \%$ of the control, respectively. At 7-8 months, those values returned completely to the preinfusion levels (fig. 2). Upon multimer analysis of plasma VWF in this patient, it was obvious that VWFMs with large to medium molecular masses more selectively disappeared before the IV-Ig infusion than did those with 


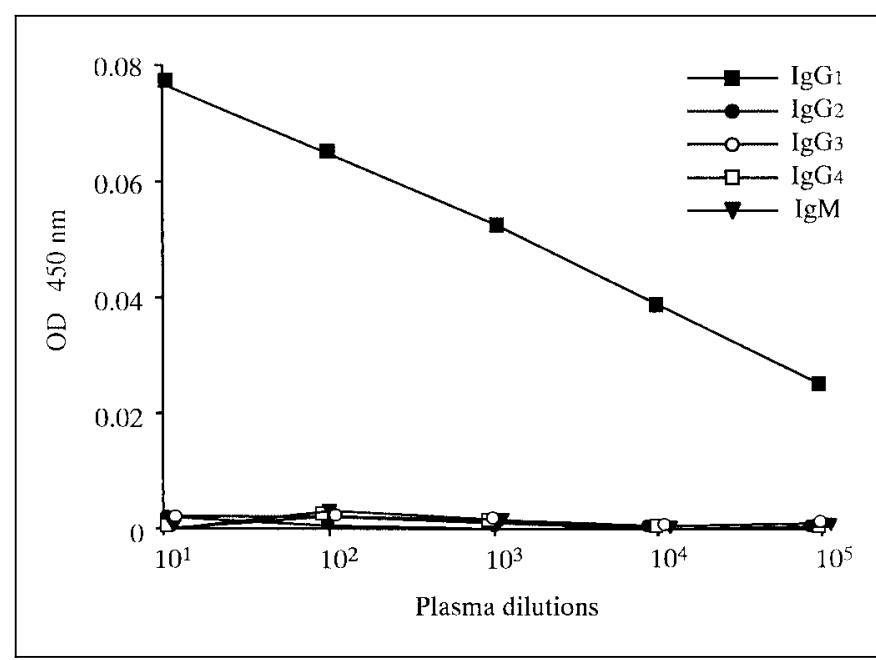

Fig. 1. Binding activity of the alloantibody against VWF and identification of the Ig subclass. Shown are dose response curves for the concentration of the anti-VWF IgG subclass and IgM subclass measured by ELISA. The method used in this assay has been described in detail elsewhere [16]. OD = Optical density.

Fig. 2. Changes in the plasma levels of VWF-Ag, VWF-RCo and inhibitor of VWF-RCo and VWF-CPase activity after low-dosage IVIg therapy.

small molecular masses. On the 4th day, the pattern of VWFMs was completely normalized and appeared to persist to the 10th day. Six months later, a small amount of large to medium-sized VWFMs was still present, but after 7-8 months, the pattern of VWFMs became almost the same as that before infusion (fig. 3). Throughout the patient's clinical course, however, plasma VWF-CPase activity was normal $(95-110 \%$ of the control), and its inhibitor was negative (below 0.1 Bethesda units $/ \mathrm{ml}$ ).

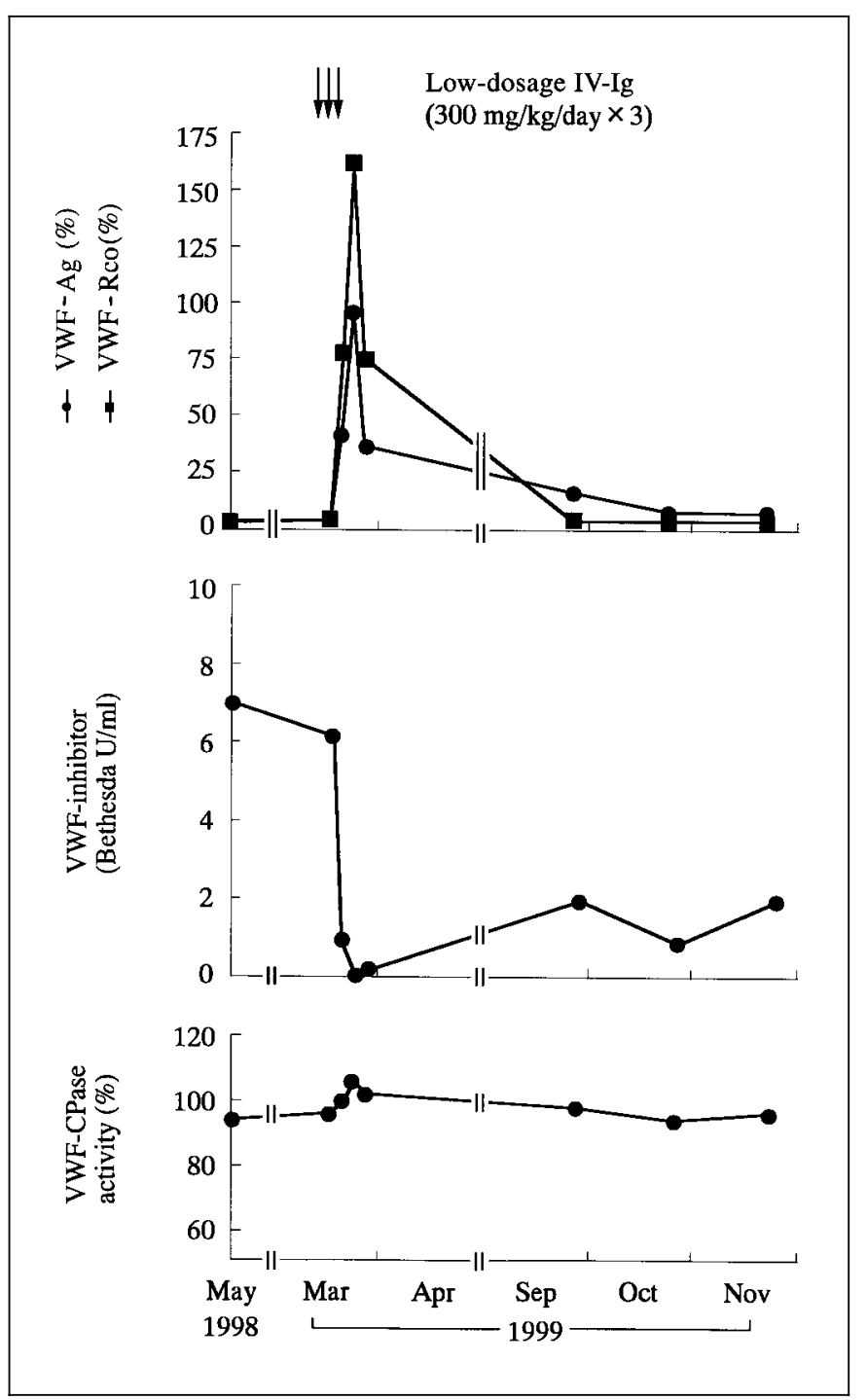

\section{Discussion}

Our patient with IgG-MGUS was urged to undergo tooth extractions because of complicated alveolar pyorrhea. Therefore, we had to choose the best hemostatic management for him from the aforementioned three therapeutic approaches. DDAVP therapy, to begin with, is undoubtedly the most inexpensive of the three. Although both DDAVP and factor VIII/VWF concentrate might have been able to increase plasma levels of VIII:C and VWF in our patient, the effect of these preparations is assumed to be only transient, usually less than several hours with a single administration [17]. Further, it is well known that repeated use of DDAVP with short intervals 
Fig. 3. Changes in VWFM pattern after lowdosage IV-Ig therapy analyzed by SDS-1.4\% agarose gel electrophoresis. Note that the large to medium-sized VWFMs are preferentially absent before and 6-8 months after low-dosage IV-Ig therapy. However, VWFMs of all sizes appear on the 4th day after low-dosage IV-Ig therapy, and they are still detected on the 10th day. Throughout the clinical course of this patient, the VWFCPase activity was normal and its inhibitor was negative, as described in Results. NP = Normal plasma; $\mathrm{D}=$ days; $\mathrm{M}=$ months.

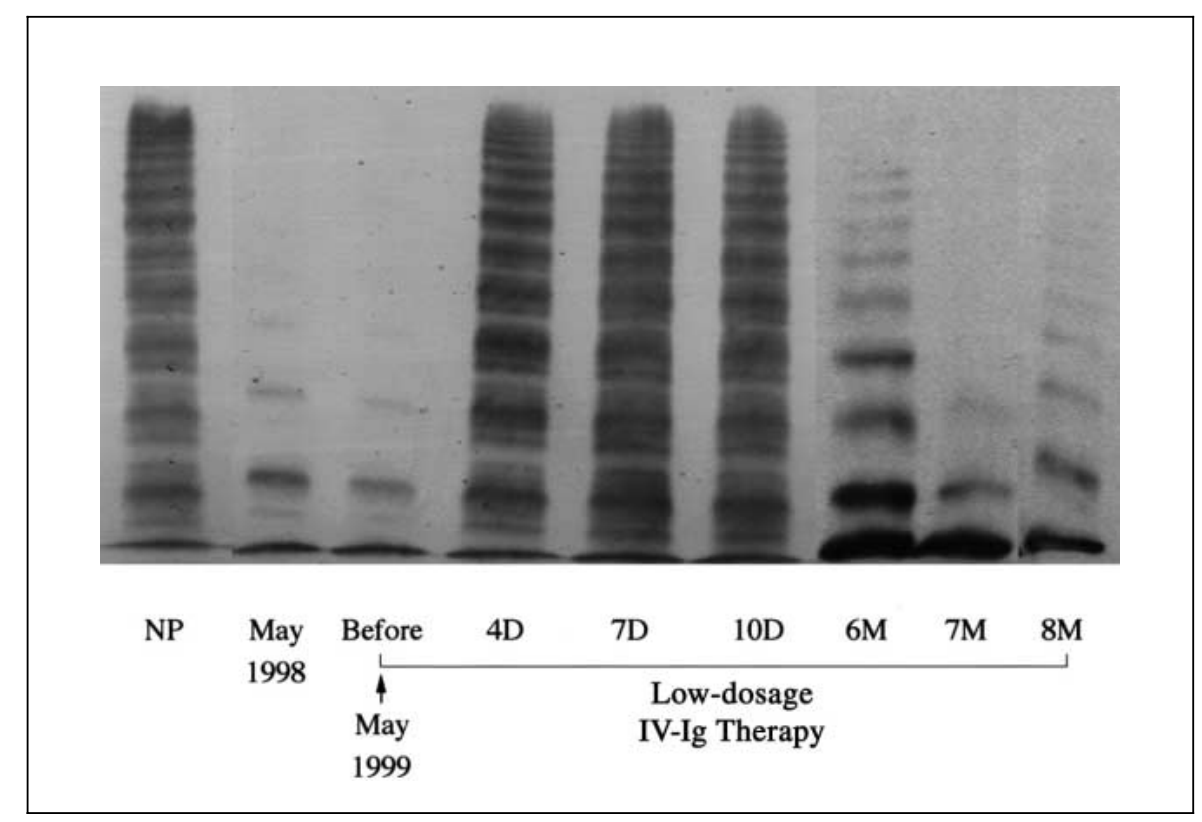

is less efficient than the first time, because of depletion of stored VWF. In this regard, it is important to note that after multiple tooth extractions in such patients, the bleeding is often long-lasting or repeated unless adequate hemostatic control is maintained during the completion of wound healing. For this purpose, a high-dosage IV-Ig therapy appears to be most suitable, because of its longacting hemostatic effect, usually $2-3$ weeks [17], but it is unambiguously very expensive. However, it is important to remember that DDAVP therapy must be the first choice for uncomplicated tooth extractions. Secondly, our patient fortunately had IgG-MGUS, because high-dosage IV-Ig therapy is known to be much less effective or of no use in patients with IgM-MGUS. Thirdly, in regard to the amount of IgG required for IV-Ig therapy, there is a conflict between two reports: Mohri et al. [18] indicated that IV-Ig therapy of $0.3 \mathrm{~g} / \mathrm{kg} /$ day for 3 days is effective to correct a hemostatic defect in patients with AVWS developing inhibitors, but Federici et al. [17] reported that the dosage of $1 \mathrm{~g} / \mathrm{kg} / \mathrm{day}$ for 2 days seems to be critical, because smaller or no responses were elicited in such patients when the dosage was tapered to 0.75 and $0.5 \mathrm{~g} /$ $\mathrm{kg}$ /day for 2 days. However, the $\mathrm{IgG}$ preparations used in these two reports were different, i.e. sulfonated [18] and intact [17] IgG, and further, the anti-VWF inhibitor titers were not described in either group of patients. Since we were able to use sulfonated IgG, which was the same preparation but different lots as Mohri et al. [18], a dose of
$0.3 \mathrm{~g} / \mathrm{kg} /$ day for 3 consecutive days was chosen. On the 4th day after the infusion, VWF-Ag and VWF-RCo increased to 40 and $78 \%$ of the control, respectively, and tooth extractions were successfully performed in our patient. On the 7 th day, these values reached the maximum throughout the patient's clinical course, i.e. 95 and $160 \%$, and then decreased to 35 and $75 \%$ on the 10th day. So, we were able to confirm the results of Mohri et al. [18] in our patient. Six months later, VWF-Ag decreased to $16 \%$ of the control and VWF-RCo was no longer detected in this patient (fig. 2). Interestingly, in our patient, VWFMs with large to medium molecular masses more selectively disappeared before and 6-8 months after IV-Ig infusion than did those with small molecular masses. Similar observations have been reported previously [19-21], but without solid evidence. However, now two possible explanations at least can be given for this mechanism: one is a heightened proteolysis of the large to medium-sized VWFMs by a specific plasma protease termed VWF-CPase under high shear stress [6, 13], and the other is a rapid clearance of IgG-VWFM complex from the circulation through its binding to the $\mathrm{Fc}$ receptor of macrophages in the reticuloendotherial system and internalization [1-4]. With regard to the former, it has been indicated that proteolytic degradation of VWFMs is heightened in patients with AVWS associated with cardiac valve diseases [2-4]. Further, patients with congenital or acquired valvular heart disease may often have a lack of the large VWFMs, which 
is normalized after valve replacement [2-4]. These results suggest the importance of VWF-CPase, together with high shear stress generated in the altered circulatory system. With regard to the latter possible mechanism, it seems to be true that the clearance from the circulation of the complex of IgG and VWFMs with large to medium molecular masses, which has more $\mathrm{Fc}$ regions, can be accelerated in comparison to that of complexes with VWFMs with smaller molecular masses. Our patient had no valvular heart disease, and further we have shown here that he had quite normal activity of plasma VWF-CPase, which was almost unchanged by the low-dose IV-Ig infusion. Thus, a selective disappearance of large to medium-sized VWFMs in our patient can presumably be attributed to the latter mechanism. The additional mechanisms, although appearing to be implausible, remain to be investigated as follows: (1) the Ig preparation used may have anti-idiotypic antibodies or a direct effect on antibodyproducing cells [1-4], or (2) the Ig preparation may have an activity in stimulating endothelial cells, thus producing and releasing more VWF [1-4]. In contrast, for AVWS of the nonantibody type, another mechanism, such as the selective absorption of VWFMs on clonal lymphocytes or plasma cells [22-24], has been postulated, because some clonal cells in those patients may express platelet glycoprotein Ib, a VWF receptor, on their surface. However, this is not the case in our patient.
In conclusion, we showed here that when a diagnosis of IgG antibody-induced AVWS associated with MGUS is made, the hemostatic management of such patients can be performed with low-dosage IV-Ig therapy. The VWF parameters can be almost normalized on the 4th day after infusion, and this condition continues for at least 7 days without additional infusions. The cost of a low-dosage IVIg therapy is simply calculated to be a $55 \%$ reduction compared to a high-dosage IV-Ig therapy, and presumably a greater reduction than that with inhibitor neutralization therapy using VWF concentrates. Thus, low-dosage IV-Ig therapy is recommended as a first choice for programmed surgery in patients with AVWS associated with MGUS with IgG antibodies. Our experience, however, may suggest that the dose and duration of administration of IV-Ig is worth reevaluating, based on the molecular design of IgG preparations or the anti-VWF inhibitor titer of the recipients.

\section{Acknowledgments}

This work was supported in part by research grants from the Ministry of Education, Culture, Sports, Science and Technology of Japan (to Y.F.) and from the Ministry of Health and Welfare of Japan for Blood Coagulation Abnormalities H11-02 (to Y.F.).

\section{References}

1 Mannucci PM, Lombardi R, Bader R, Horellou MH, Finazzi G, Besana C, Conard J, Samama M: Studies of the pathophysiology of acquired von Willebrand's disease in seven patients with lymphoproliferative disorders or benign monoclonal gammopathies. Blood 1984; 64:614-621.

2 Rinder MR, Richard RE, Rinder HM: Acquired von Willebrand's disease: A concise review. Am J Hematol 1997;54:139-145.

3 Veyradier A, Jenkins CS, Fressinaud E, Meyer D: Acquired von Willebrand syndrome: From pathophysiology to management. Thromb Haemost 2000;84:175-182.

4 Federici AB, Rand JH, Bucciarelli P, Budde U, van Genderen PJJ, Mohri H, Meyer D, Rodeghiero F, Sadler JE: Acquired von Willebrand syndrome: Data from an international registry. On behalf of the subcommittee on von Willebrand factor. Thromb Haemost 2000;84:345349.

5 Ruggeri ZM, Ware J: von Willebrand factor. FASEB J 1993; 7:308-316.
6 Furlan M, Robles R, Solenthaler M, Wassmer M, Sandoz P, Lämmle B: Deficient activity of von Willebrand factor-cleaving protease in chronic relapsing thrombotic thrombocytopenic purpura. Blood 1997;89:3097-3103.

7 Fujimura Y, Ikeda Y, Miura S, Yoshida E, Shima H, Nishida S, Suzuki M, Titani K, Taniuchi $\mathrm{Y}$, Kawasaki T: Isolation and characterization of jararaca GPIb-BP, a snake venom antagonist specific to platelet glycoprotein Ib. Thromb Haemost 1995; 74:743-750.

8 Hardisty RM, MacPherson JC: A one-stage factor VIII (anti-haemophilic globulin) assay and its use on venous and capillary plasma. Thromb Diath Haemorrh 1962;7:215-229.

9 Bartlett A, Dormandy KM, Hawkey CM, Stableforth P, Voller A: Factor-VIII-related antigen: Measurement by enzyme immunoassay. Br Med J 1976;i:994-996.

10 Macfarlane DE, Stibbe J, Kirby EP, Zucker MB, Grant RA, McPherson J: A method for assaying von Willebrand factor (ristocetin cofactor). Thromb Diath Haemorrh 1975;34: 306-308.
11 Kasper CK, Alendon LM, Counts RB, Edson JR, Fratantoni J, Green D, Hampton JW, Hilgartner MW, Lazerson J, Levine PH, McMillan CW, Pool JG, Shapiro SS, Shulman NR, van Eys J: A more uniform measurement of factor VIII inhibitors. Thromb Diath Haematol 1975; 34:869-872.

12 Kinoshita S, Yoshioka A, Park Y-D, Ishizashi H, Konno M, Funato M, Matsui T, Titani K, Yagi H, Matsumoto M, Fujimura Y: UpshawSchulman syndrome revisited: A concept of congenital thrombotic thrombocytopenic purpura. Int J Hematol 2001;74:101-108.

13 Yagi H, Konno M, Kinoshita S, Matsumoto M, Ishizashi H, Matsui T, Titani K, Fujimura Y: Plasma of patients with Upshaw-Schulman syndrome, a congenital deficiency of von Willebrand factor-cleaving protease, enhances the aggregation of normal platelets under high shear stress. Br J Haematol 2001;115:991997.

14 Ruggeri ZM, Zimmerman TS: The complex multimeric composition of factor VIII/von Willebrand factor. Blood 1981;57:1140-1143. 
15 Budde U, Schneppenheim R, Plendl H, Dent J, Ruggeri ZM, Zimmerman TS: Luminographic detection of von Willebrand factor multimers in agarose gels and on nitrocellulose membranes. Thromb Haemost 1990;63:312-315.

16 Shibata M, Shima M, Fujimura Y, Takahashi Y, Nakai H, Sakurai Y, Asatani M, Nomura A, Take H, Giddings JC, Yoshioka A: Identification of the binding site for an alloantibody to von Willebrand factor which inhibits binding to glycoprotein $\mathrm{Ib}$ within the amino-terminal region flanking the A1 domain. Thromb Haemost 1999;81:793-798.

17 Federici AB, Stabile F, Castaman G, Canciani MT, Mannucci PM: Treatment of acquired von Willebrand syndrome in patients with monoclonal gammopathy of uncertain significance: Comparison of three different therapeutic approaches. Blood 1998;92:2707-2711.
18 Mohri H, Motomura S, Kanamori H, Matsuzaki M, Watanabe S, Maruta A, Kodama F, Okubo T: Clinical significance of inhibitors in acquired von Willebrand syndrome. Blood 1998; 91:3623-3629.

19 Macik BG, Gabriel DA, White GC II, High K, Roberts $\mathrm{H}$ : The use of high-dose intravenous $\gamma$-globulin in acquired von Willebrand syndrome. Arch Pathol Lab Med 1988;112:143146.

20 Meyer D, Frommel D, Larrieu MJ, Zimmerman TS: Selective absence of large forms of factor VIII/von Willebrand factor in acquired von Willebrand's syndrome. Response to transfusion. Blood 1979;54:600-606.

21 López-Fernández MF, López-Berges C, Martín R, Nieto J, del Rio F, López-Borrasca A, Batlle $\mathrm{J}$ : Unique multimeric pattern of von Willebrand factor in a patient with a benign monoclonal gammopathy. Scand J Haematol 1986; 36:302-308
22 Takahashi H, Nagayama R, Tanabe Y, Satoh K, Hanano M, Mito M, Shibata A: DDAVP in acquired von Willebrand syndrome associated with multiple myeloma. Am J Hematol 1986; 22:421-429.

23 Brody JI, Haidar ME, Rossman RE: A hemorrhagic syndrome in Waldenström's macroglobulinemia secondary to immunoadsorption of factor VIII. Recovery after splenectomy. N Engl J Med 1979;300:408-410.

24 Richard C, Cuadrado MA, Prieto M, Batlle J, López-Fernández MF, Rodriguez-Salazar ML, Bello C, Recio M, Santoro T, Gomez-Casares MT, Zubizarreta A: Acquired von Willebrand disease in multiple myeloma secondary to absorption of von Willebrand factor by plasma cells. Am J Hematol 1990;35:114-117. 